\title{
Novel development in extraintestinal manifestations and spondylarthropathy
}

\author{
De Vos M, MD.PhD - Hindryckx P, MD - Laukens D, PhD \\ Department Gastroenterology \\ Ghent University Hospital \\ Belgium
}

\begin{abstract}
The important co-existence of spondylarthritis (SpA) and inflammatory bowel disease (IBD) within the same individual suggests common etiopathogenic mechanisms. This is supported by intriguing similarities between both diseases at the subclinical and molecular level. The recent advances in IBD genetics have led to the identification of common pathways involved in both IBD and SpA, including bacterial recognition and ER stress. This offers the opportunity to develop potential new therapeutic strategies for both diseases. Transgenic animals which develop both joint and gut inflammation (like the $\mathrm{TNF}^{\triangle \mathrm{ARE}}$ mice and the HLAB27 transgenic rats) are a very useful tool to test such novel therapeutics and to get further mechanistic insight into the pathogenetic link between SpA and IBD.

This review will focus on the recent scientific progress in our understanding of the link between SpA and IBD. Based on this, potential novel therapeutic strategies are discussed.
\end{abstract}




\section{Introduction}

The extraintestinal manifestations of inflammatory bowel disease (IBD) include peripheral and axial arthropathy in $20 \%$ of patients, skin involvement in $20 \%$ of patients, uveitis in $8 \%$ and liver disease in $6 \%$ of patients. The arthropathy observed in IBD belongs to the concept of spondylarthropathy (SpA) and includes a transient, migratory and mostly non-deforming arthritis and/or an inflammatory back pain associated with sacroiliitis and spondylitis. On the other hand, extra-articular manifestations of SpA include IBD in $20 \%$ of patients, psoriasis in $20 \%$ of patients and uveitis in $51 \%$ of patients. Characteristic for gut, joint, skin and eye disease is the well-proven effect of TNF- $\alpha$ blockers, suggesting a central role of TNF- $\alpha$ in these immune-mediated inflammatory diseases.

Besides the important coincidence of IBD and SpA, an intriguing link between both disorders is found at the subclinical level. On the one hand, asymptomatic sacroiliitis is present on radiography in $16 \%$ of patients with IBD. However, when using MRI to detect sacroiliitis, the prevalence will probably be much higher, as it has been demonstrated that the clinical stage of inflammation is preceded by abnormalities on MRI including oedema of the cartilaginous portion of the sacroiliac joint and fat deposition in the subchondral bone marrow followed by the well-known erosions of joint facets and narrowing of joint space [1]. On the other hand, subclinical gut inflammation has been described in $60 \%$ of patients with SpA including in $25 \%$ of patients a chronic gut inflammation with increased risk for the development of overt IBD [2].

Based on recent literature, this review aims to give an overview of the processes involved in both joint and gut inflammation. 
De Vos et al.

\section{Animal models for the study of combined inflammatory bowel disease and spondylarthropathy \\ $T N F^{\triangle A R E}$ mice}

The $\mathrm{TNF}^{\triangle \mathrm{ARE}}$ mouse model is characterized by a 69 base pair deletion of TNF- $\alpha$ AU-rich elements from the mouse genome leading to steady-state increased TNF- $\alpha$ mRNA levels in hematopoietic and stromal cells as well as a diminished translational silencing of the TNF- $\alpha$ mRNA. Starting at the age of 5 weeks, the animals spontaneously develop an inflammatory disease characterized by CD-like chronic ileitis and SpA-like sacroiliitis, achilles tendon enthesitis and peripheral arthritis. Therefore, this is an ideal model to study the relationship between CD and SpA [3].

Using micro-CT scan after oral gavage with Gastrografin and a micro-Positron Emission Tomography scan (PET) after intravenous injection of 2-deoxy-2(17F)fluoro-d-glucose, we were able to illustrate and quantify inflammation in the terminal ileum and the joints in this animal model [4]. As such, this technique represents a very attractive tool to study therapeutic interventions (see figure 1).

\section{HLA-B27 transgenic rats}

The HLA-B27 transgenic rat model was created by microinjection of the human HLA-B27 and $\beta 2$-microglobulin genes into rat zygotes. By expressing HLA-B27 and $\beta 2$-microglobulin, these rats develop spondylarthritis, inflammatory bowel disease (which mainly affects the colon), psoriasis vulgaris and genital inflammation [5].

\section{Mechanism based future treatment modalities in IBD and SpA}

Two different approaches can be used to shape the fundaments for future treatment modalities in IBD and SpA. Firstly, the search for common susceptibility genes linking different human 
immune mediated inflammatory diseases may help to identify potential common etiopathogenetic pathways leading to disease (see figure 2). Secondly, interventional studies in $\mathrm{TNF}^{\triangle \mathrm{ARE}}$ mice and HLA-B27 transgenic rats will be useful to study the effect of potential therapeutics on both gut and joint inflammation.

\section{Common susceptibility genes and associated pathways}

\section{CARD15, bacterial recognition and $\mathrm{NF} \kappa \mathrm{B}$ activation}

The first susceptibility gene that has been identified for CD is CARD15, also known as NOD2. Variants within this gene increase the risk for CD by threefold for heterozygous individuals and 33-44 fold for homozygous and compound heterozygous individuals. Several studies excluded an association between CARD15 variants and AS or SpA in IBD populations [611]. However an association was found in SpA patients between the carriage of CARD15 variants and the development of chronic subclinical gut inflammation, with odds ratio's of 2.9 as compared to control population and of 5.8 as compared to SpA patients without gut inflammation [11]. Although CARD15 mutations do not seem to predispose to joint inflammation in SpA patients, it might confer a risk towards the development of (sub)clinical gut inflammation, rendering these patients more prone to develop overt IBD. In order to use such a marker to predict patient outcome, long-term follow-up studies are necessary. However, a CARD15-mediated NFKB-dependent inflammatory reaction might be an important pathogenic process within the joints [12]. In Blau syndrome, characterized by inflammatory arthritis, uveitis and dermatitis, a definite link was found with the carriage of mutations in the CARD15 gene. The protein is expressed in joint tissue, and bacterial cell wall components have been demonstrated in synovium of SpA patients, supporting the idea that CARD15 can locally trigger inflammation. It has been demonstrated that the activation of CARD15 in synovial fibroblasts from patients with reumatoid arthritis acts synergistically 
with Toll like receptors in the production of pro-inflammatory and destructive mediators [13]. Finally , CARD15-deficient mice do not develop arthritis upon direct local challenge with peptidoglycan, whereas wild type mice do [14].

\section{The IL23/T helper 17 (Th17) axis}

A second important associated gene complex for IBD that has been identified through genome-wide association is the pathway leading to T helper 17 (Th17) cell development [15]. These $\mathrm{T}$ cells produce a specific cytokine pattern, specifically IL17A, IL17F, IL22, TNF- $\alpha$ and IL6. Differentiation of these TH17 cells is induced by TGFb and IL21, while the perpetuation of the Th17 cell program is mediated by IL23R signalling. Retinoic acid receptor-related orphan receptor gamma (ROR gamma), but also RORalpha was shown to regulate Th17 differentiation [16].

Both protective and risk variants in the $I L 23 R$ gene have been found associated with both CD and AS [17, 18]. Other variants in genes involved in IL23R signalling and Th17 differentiation have been described in IBD (IL12B, STAT3, JAK2, and CCR6) but their relevance still needs to be studied in SpA.

The functional consequence of genetic variants within the IL23/Th17 axis on the normal execution of this pathway is not well studied. A major draw-back is the low allele frequency of the associated variants, and therefore the lack of sufficiently large numbers of patients to be studied. Nevertheless, it is clear that in general Th17 effector cytokines are aberrantly expressed in affected tissues of patients with CD as well as of patients with AS. A specific expression signature of IL23 an IL17 has been found in patients with subclinical chronic gut inflammation: IL23 gene expression is increased in terminal ileum of AS patients, but unlike in CD, IL17 is not induced [19]. 
IL17 differentiation and effector cytokines are increased in intestinal mucosa of IBD patients and seems higher in active ulcerative colitis than Crohn colitis [20]. Intriguingly, the expression of Th17 differentiation factors in active Crohn ileitis is not changed as compared to healthy ileal tissue unless for the effector cytokines IL17 and IL22 (unpublished data).

The role of IL17A/IL17F in intestinal inflammatory colitis may be dual: neutralisation of IL17A and/or IL17F in animal models of colitis leads to contradictory results [21, 22]. Together, these findings suggest that a neutralisation of Th17 effector cytokines as therapeutic target or a neutralisation of ROR gamma deserves attention, with possibly different effects in colonic and ileal inflammation.

\section{HLA-B27 and endoplasmic reticulum stress}

The most studied gene of interest for AS is the HLA-B27 gene. The association of HLA-B27 with arthritis is found in $90 \%$ of patients with AS without IBD, 25-70\% of patients with AS and IBD but only in $7 \%$ of patients with IBD and sacroiliitis and $7 \%$ of patients with IBD alone.

In HLA-B27 expressing macrophages, IL23 was synergistically up-regulated in response to lipopolysaccharide stimulation [23]. In addition, IL23 and IL17 were strongly expressed in the colon of HLA-B27 transgenic rats

The trimer heavy chain of HLA-B27 has a tendency to misfold in the endoplasmic reticulum (ER) and activate the unfolded protein response (UPR) which induces profound changes in the cellular metabolism [24]. One of these changes includes an inhibition of the translation and the transcription of molecular chaperone genes and results in a downstream inflammation [25].

An important role for ER stress in IBD is emerging: association between variants in one of the key components of ER stress (XBP1) with CD and UC has been demonstrated. Moreover a 
deletion of XBP1 in intraepithelial cells induces a spontaneous enteritis secondary to Paneth cell dysfunction and over-reactive epithelium to bacterial products and TNF- $\alpha$ [26].

We have recently provided additional evidence supporting a key role of ER stress in both gut and joint inflammation. A study of mucosal gene expression profiles in IBD and SpA patients revealed an aberrant expression of metallothioneins [27]. These are acute stress proteins able to alleviate oxidative-stress induced ER stress in cardiac disease [28-30]. A recent association study in a cohort of $182 \mathrm{AS}$ patients for SNP markers corresponding to $40 \mathrm{CD}$ risk loci described by Barrett and colleagues identified a common association with a locus linked with ORMDL3 gene expression, a gene involved in protein folding and ER stress [31, 32].

\section{Interventional studies in $T_{N F^{\Delta A R E}}$ mice}

\section{Prolyl hydroxylase inhibitors}

Chronic inflammation is associated with increased consumption and disturbed delivery of oxygen, resulting in profound hypoxia at the site of inflammation [33].

Hypoxia-inducible factor-1 (HIF-1) is the master regulator of cellular responses to low oxygen levels. During hypoxia, HIF-1 is stabilized through inhibition of "oxygen-sensing" prolyl hydroxylases, resulting in an adaptive gene transcription programme, which is essential for both enterocyte and chrondrocyte cell function and cell survival [34]. We found that the prolyl hydroxylase inhibitor dimethyloxalylglycin (DMOG) protects intestinal epithelial cells against TNF- $\alpha$-induced cell death through HIF-1-dependent repression of Fas-associated death domain protein (FADD), a critical adaptor protein in TNFR-1-mediated apoptosis [35]. This anti-apoptotic action at least in part contributes to a fast restoration of barrier function and dampening of the chronic intestinal inflammation in $\mathrm{TNF}^{\triangle \mathrm{ARE}}$ mice treated with DMOG. However, DMOG was not effective in the concomitant arthritis of these mice, possibly because DMOG is a non-selective hydroxylase inhibitor which also disturbs proper collagen 
formation through interference with collagen hydroxylases [36]. The development of more specific HIF-hydroxylase inhibitors is eagerly awaited.

\section{CD $8 \alpha \beta$ lymphocyte inhibitors}

Ileal inflammation is associated with a decline of potentially protective TCR $\alpha \beta C D 8 \alpha \alpha$ and TCR $\gamma \delta$ lymphocytes early in the disease process and the predominance of TNF/IFN- $\gamma$ producing CD8 $\alpha \beta$ lymphocytes in the epithelium [37]. Additionally, a decrease in IFN- $\gamma+$

CD4 intraepithelial lymphocytes is found. The IFN- $\gamma$ dependence of the TNF ${ }^{\triangle A R E}$ model may be related to IFN- $\gamma$ producing $\mathrm{CD} 8 \alpha \beta$ intraepithelial lymphocytes rather than Th1 CD4 Tlymphocyte response.

In the lamina propria (LP), a significant increased $\mathrm{CD} 4 / \mathrm{CD} 8 \alpha \beta$ ratio is observed as compared with wild type mice [37]. Lamina propria CD4 lymphocytes are characterized by decreased expression of IFN- $\gamma$ and increased expression of IL17 and IL10. CD8 $\alpha \beta$ lymphocytes from the LP of both normal and diseased animals highly express IFN- $\gamma$ indicating a decreased Th1 and increased Th17 CD4 T-cell response in the inflamed LP and the persistent capacity of LP CD8 $\alpha \beta$ lymphocytes for IFN- $\gamma$ production.

\section{Selective TNFR1 inhibitors}

Signalling through TNFRI in synovial fibroblasts and intestinal myofibroblasts appeared to be sufficient to develop combined gut and joint inflammation in $\mathrm{TNF}^{\triangle \mathrm{ARE}}$ mice, providing the first strong evidence for a common pathophysiologic mechanism and suggests that attenuation of this pathway may hold promise for more rational and effective therapeutic interventions [38]. 
Invariant natural killer T-cell (iNKT cell) activators

Absence of invariant natural killer T-cells (iNKT cells) aggravates articular and ileal inflammation in $\mathrm{TNF}^{\triangle \mathrm{ARE}}$ mice. Chronic dysregulated TNF- $\alpha$ production activates iNKT cells by influencing their cross-talk with dendritic cells and as such, induces a counter-regulatory mechanism for dampening TNF- $\alpha$-driven inflammation [39]. Activators of iNKT cells may thus represent a promising therapy for immune-mediated inflammatory disease.

\section{Leukocyte homing inhibitors}

The selective recruitment of leukocytes from the circulation to the target tissues is controlled through the interaction of adhesion molecules and chemokine receptors with their corresponding ligands. Ileal inflammation is associated with an increased $\alpha E \beta 7$ integrin expression in peripheral activated/memory intestinal-homing CD8 $\alpha \beta$ lymphocytes. A similar enrichment of $\mathrm{T}$ cells carrying $\beta 7$ integrins was found in inflamed synovial tissue from patients with early SpA [40]. Genetic ablation of $\beta 7$ integrin protects mice against ileitis whereas absence of chemokine/chemokine receptor pair CCL25/CCR9 has no influence on inflammation, supporting the idea that CCR9-independent pathways of T-lymphocyte recruitment to the ileum are responsible for lymphocyte accumulation and disease pathogenesis in CD8-dependent TNF- $\alpha$-driven CD [37].

\section{Selective kinase blockade}

Selective blockade of Jun N-terminal Kinase 2 (JNK2) and tumour progression locus 2 (Tp12) kinase is associated with an improvement of enterocolitis, whereas blockade of p38/MAPK-activated protein kinase 2 (p38/MK2) increases intestinal inflammation [41]. 


\section{Summary}

The advances in techniques to study genetic predisposition of complex diseases can significantly aid to understand associated disease manifestations such as arthropathy. In this way, previously unidentified pathways such as bacterial recognition and ER stress were linked with both IBD and SpA. Finally, an elegant way to study these processes and to test therapeutic potential is the use of the $\mathrm{TNF}^{\Delta \text { are }}$ and HLA-B27 transgenic models.

\section{Conflict of interest}

None

\section{Acknowledgements}

The authors wish to thank Steven Staelens en Steven Deleye (Medical Signal and Image Processing group, Ghent University-IBBT, Ghent, Belgium and Faculty of Medicine, Molecular Imaging Center Antwerp, Antwerp University, Antwerp, Belgium) for acquisition of the PET/CT images.

\section{References}

1. Madsen KB, Schiottz-Christensen B, Jurik AG (2010). Prognostic significance of magnetic resonance imaging changes of the sacroiliac joints in spondyloarthritis--a followup study. J Rheumatol 37: 1718-27.

2. De Vos M, Mielants H, Cuvelier C, Elewaut A, Veys E (1996). Long-term evolution of gut inflammation in patients with spondyloarthropathy. Gastroenterology 110 : 1696-703.

3. Kontoyiannis D, Pasparakis M, Pizarro TT, Cominelli F, Kollias G (1999). Impaired on/off regulation of TNF biosynthesis in mice lacking TNF AU-rich elements: implications for joint and gut-associated immunopathologies. Immunity 10: 387-98.

4. Hindryckx P, Staelens S, Deleye S, Peeters H, Laukens D, De Vos M (2010). Small Animal PET-CT as a Non-Invasive Method to Evaluate Terminal Ileal Inflammation in a Murine Model of Crohn's Disease. Gastroenterology 138: S-514-S-5 
5. Hammer RE, Maika SD, Richardson JA, Tang JP, Taurog JD (1990). Spontaneous inflammatory disease in transgenic rats expressing HLA-B27 and human beta $2 \mathrm{~m}$ : an animal model of HLA-B27-associated human disorders. Cell 63: 1099-112.

6. van der Paardt M, Crusius JB, de Koning MH, Murillo LS, van de Stadt RJ, Dijkmans BA et al. (2003). CARD15 gene mutations are not associated with ankylosing spondylitis. Genes Immun 4: 77-8.

7. Kim TH, Rahman P, Jun JB, Lee HS, Park YW, Im HJ et al. (2004). Analysis of CARD15 polymorphisms in Korean patients with ankylosing spondylitis reveals absence of common variants seen in western populations. J Rheumatol 31: 1959-61.

8. Crane AM, Bradbury L, van Heel DA, McGovern DP, Brophy S, Rubin L et al. (2002). Role of NOD2 variants in spondylarthritis. Arthritis Rheum 46: 1629-33.

9. D'Amato M (2002). The Crohn's associated NOD2 3020InsC frameshift mutation does not confer susceptibility to ankylosing spondylitis. J Rheumatol 29: 2470-1.

10. Ferreiros-Vidal I, Amarelo J, Barros F, Carracedo A, Gomez-Reino JJ, Gonzalez A (2003). Lack of association of ankylosing spondylitis with the most common NOD2 susceptibility alleles to Crohn's disease. J Rheumatol 30: 102-4.

11. Laukens D, Peeters H, Marichal D, Vander Cruyssen B, Mielants H, Elewaut D et al. (2005). CARD15 gene polymorphisms in patients with spondyloarthropathies identify a specific phenotype previously related to Crohn's disease. Ann Rheum Dis 64: 930-5.

12. Miceli-Richard C, Zouali H, Lesage S, Thomas G, Hugot JP, Said-Nahal R et al. (2002). CARD15/NOD2 analyses in spondylarthropathy. Arthritis Rheum 46: 1405-6.

13. Ospelt C, Brentano F, Jungel A, Rengel Y, Kolling C, Michel BA et al. (2009). Expression, regulation, and signaling of the pattern-recognition receptor nucleotidebinding oligomerization domain 2 in rheumatoid arthritis synovial fibroblasts. Arthritis Rheum 60: 355-63.

14. Rosenzweig HL, Jann MJ, Vance EE, Planck SR, Rosenbaum JT, Davey MP (2010). Nucleotide-binding oligomerization domain 2 and Toll-like receptor 2 function independently in a murine model of arthritis triggered by intraarticular peptidoglycan. Arthritis Rheum 62: 1051-9.

15. Barrett JC, Hansoul S, Nicolae DL, Cho JH, Duerr RH, Rioux JD et al. (2008). Genome-wide association defines more than 30 distinct susceptibility loci for Crohn's disease. Nat Genet 40: 955-62.

16. Yang XO, Pappu BP, Nurieva R, Akimzhanov A, Kang HS, Chung Y et al. (2008). T helper 17 lineage differentiation is programmed by orphan nuclear receptors ROR alpha and ROR gamma. Immunity 28: 29-39.

17. Rahman P, Inman RD, Gladman DD, Reeve J, Wang N, Peddle L et al. (2007). Association of IL-23R variants and ankylosing spondylitis (AS). Ann Rheum Dis 66: 83.

18. Reveille JD, Zhou X, Bradbury LA, Cardon LR, Davis JC, Deloukas P et al. (2007). IL-23R is a major determinant of ankylosing spondylitis risk - the TASC study. Ann Rheum Dis 66: 112.

19. Ciccia F, Bombardieri M, Principato A, Giardina A, Tripodo C, Porcasi R et al. (2009). Overexpression of interleukin-23, but not interleukin-17, as an immunologic signature of subclinical intestinal inflammation in ankylosing spondylitis. Arthritis Rheum 60: 955-65.

20. Seiderer J, Elben I, Diegelmann J, Glas J, Stallhofer J, Tillack C et al. (2008). Role of the novel Th17 cytokine IL-17F in inflammatory bowel disease (IBD): upregulated colonic IL-17F expression in active Crohn's disease and analysis of the IL17F p.His161Arg polymorphism in IBD. Inflamm Bowel Dis 14: 437-45. 
21. Leppkes M, Becker C, Ivanov, II, Hirth S, Wirtz S, Neufert C et al. (2009). RORgamma-expressing Th17 cells induce murine chronic intestinal inflammation via redundant effects of IL-17A and IL-17F. Gastroenterology 136: 257-67.

22. Yang XO, Chang SH, Park H, Nurieva R, Shah B, Acero L et al. (2008). Regulation of inflammatory responses by IL-17F. J Exp Med 205: 1063-75.

23. DeLay ML, Turner MJ, Klenk EI, Smith JA, Sowders DP, Colbert RA (2009). HLAB27 misfolding and the unfolded protein response augment interleukin-23 production and are associated with Th17 activation in transgenic rats. Arthritis Rheum 60: 263343.

24. Turner MJ, Sowders DP, DeLay ML, Mohapatra R, Bai S, Smith JA et al. (2005). HLA-B27 misfolding in transgenic rats is associated with activation of the unfolded protein response. J Immunol 175: 2438-48.

25. Smith JA, Turner MJ, DeLay ML, Klenk EI, Sowders DP, Colbert RA (2008). Endoplasmic reticulum stress and the unfolded protein response are linked to synergistic IFN-beta induction via X-box binding protein 1. Eur J Immunol 38: 1194203.

26. Kaser A, Lee AH, Franke A, Glickman JN, Zeissig S, Tilg H et al. (2008). XBP1 links ER stress to intestinal inflammation and confers genetic risk for human inflammatory bowel disease. Cell 134: 743-56.

27. Laukens D, Peeters H, Waeytens A, Bogaert S, Vander Cruyssen B, Elewaut D et al. (2008). Reduced metallothionein expression in colonic Crohn's disease: evidence for a new disease-modifying gene. Gastroenterology 134: A-457.

28. Guo R, Ma H, Gao F, Zhong L, Ren J (2009). Metallothionein alleviates oxidative stress-induced endoplasmic reticulum stress and myocardial dysfunction. J Mol Cell Cardiol 47: 228-37.

29. Xu J, Wang G, Wang Y, Liu Q, Xu W, Tan Y et al. (2009). Diabetes- and angiotensin II-induced cardiac endoplasmic reticulum stress and cell death: metallothionein protection. J Cell Mol Med 13: 1499-512.

30. Ceylan-Isik AF, Zhao P, Zhang B, Xiao X, Su G, Ren J (2009). Cardiac overexpression of metallothionein rescues cardiac contractile dysfunction and endoplasmic reticulum stress but not autophagy in sepsis. J Mol Cell Cardiol 48: 36778.

31. Cantero-Recasens G, Fandos C, Rubio-Moscardo F, Valverde MA, Vicente R (2010). The asthma-associated ORMDL3 gene product regulates endoplasmic reticulummediated calcium signaling and cellular stress. Hum Mol Genet 19: 111-21.

32. Laukens D, Georges M, Libioulle C, Sandor C, Mni M, Vander Cruyssen B et al. (2010). Evidence for significant overlap between common risk variants for Crohn's disease and ankylosing spondylitis. . PLos ONE Accepted for publication.

33. Taylor CT, Colgan SP (2007). Hypoxia and gastrointestinal disease. J Mol Med 85: 1295-300.

34. Semenza GL (2009). Regulation of oxygen homeostasis by hypoxia-inducible factor 1 . Physiology (Bethesda) 24: 97-106.

35. Hindryckx P, De Vos M, Jacques P, Ferdinande L, Peeters H, Olievier K et al. (2010). Hydroxylase inhibition abrogates TNF- $\alpha$-induced intestinal epithelial damage by HIF1-dependent repression of Fas-associated death domain $\mathrm{J}$ Immunol Accepted for publication.

36. Thoms BL, Murphy CL (2010). Inhibition of hypoxia-inducible factor-targeting prolyl hydroxylase domain-containing protein 2 (PHD2) enhances matrix synthesis by human chondrocytes. J Biol Chem 285: 20472-80. 
37. Apostolaki M, Manoloukos M, Roulis M, Wurbel MA, Muller W, Papadakis KA et al. (2008). Role of beta7 integrin and the chemokine/chemokine receptor pair CCL25/CCR9 in modeled TNF-dependent Crohn's disease. Gastroenterology 134: 2025-35.

38. Armaka M, Apostolaki M, Jacques P, Kontoyiannis DL, Elewaut D, Kollias G (2008). Mesenchymal cell targeting by TNF as a common pathogenic principle in chronic inflammatory joint and intestinal diseases. J Exp Med 205: 331-7.

39. Jacques P, Venken K, Van Beneden K, Hammad H, Seeuws S, Drennan MB et al. (2010). Invariant natural killer T cells are natural regulators of murine spondylarthritis. Arthritis Rheum 62: 988-99.

40. Elewaut D, De Keyser F, Van Den Bosch F, Lazarovits AI, De Vos M, Cuvelier C et al. (1998). Enrichment of T cells carrying beta7 integrins in inflamed synovial tissue from patients with early spondyloarthropathy, compared to rheumatoid arthritis. J Rheumatol 25: 1932-7.

41. Kontoyiannis D, Boulougouris G, Manoloukos M, Armaka M, Apostolaki M, Pizarro $\mathrm{T}$ et al. (2002). Genetic dissection of the cellular pathways and signaling mechanisms in modeled tumor necrosis factor-induced Crohn's-like inflammatory bowel disease. $\mathbf{J}$ Exp Med 196: 1563-74.

Figure legends

Figure 1: Assessment of intestinal and articular inflammation through non-invasive micro-PET/CT scanning, using FDG as a PET-tracer.

A: mouse positioned for micro-PET/CT scan. B: CT-image after oral contrast (gastrografin) administration, allowing easy identification of the terminal ileum (arrow).

C and D: Detailed CT-images of the terminal ileum of a 16-week old $\mathrm{TNF}^{\triangle \mathrm{ARE}}$ mouse with (D) and without (C) PET-image overlay. Note the sharp delineated FDG hot spot at the level of the terminal ileum. E and F: Detailed CT-images of the knee joint of the same animal, with (F) and without (E) PET-image overlay. Note the presence of knee joint inflammation, visualized with FDG-PET. G: Pictures of H\&E-stained terminal ileal sections of the same $\mathrm{TNF}^{\triangle \mathrm{ARE}}$ mouse (right) and a healthy littermate (left). Note the presence of increased inflammatory cell infiltrations and disturbance of the villous architecture in the $\mathrm{TNF}^{\triangle \mathrm{ARE}}$ mouse. H: PET-signal quantification at the level of the terminal ileum of the same $\mathrm{TNF}^{\triangle \mathrm{ARE}}$ 
mouse and healthy littermate, confirming highly-increased terminal ileal FDG-signal in the $\mathrm{TNF}^{\triangle \mathrm{ARE}}$ mouse.

\section{Figure 2: Common pathways involved in joint- and gut inflammation.}

Apoptosis of intestinal epithelial cells leads to a barrier breakdown. CARD15 is a bacterial receptor in the gut involved in the triggering of $\mathrm{NF}-\mathrm{\kappa B}$-mediated pro-inflammatory reaction. Th1 and Th17 responses are induced. Polymorphisms in the CARD15 gene and the IL23R gene may modulate this response.

Inflammation is characterized by microvascular dysfunction and an increased influx of oxygen-demanding inflammatory cells releasing pro-inflammatory cytokines like TNF $\alpha$, which increases epithelial apoptosis by binding to TNFRI. Resulting mucosal hypoxia also increases apoptosis of the intestinal epithelial cells and promotes the influx of intraluminal antigens into the lamina propria, which in turn sustains the inflammatory process. Induced endoplasmic reticulum stress further increases epithelial response to bacteriae and intensifies inflammatory reaction.

Activated $\mathrm{T}$ cells and macrophages carrying bacterial components migrate to the joints and may be recognized by adhesion molecules such as b7 integrins and VAP-1. CARD15 may recognize bacterial components and induces NF- $\mathrm{KB}$-dependent inflammation. The targeted joint mesenchymal cells become activated and sustain inflammation. Finally, circulation of iNKT cells dampens inflammation in gut and joints. 